\title{
QME special issue on discrete games
}

\author{
Greg Allenby
}

Published online: 22 February 2013

(C) Springer Science+Business Media New York 2013

I am pleased and excited to present this special issue of Quantitative Marketing and Economics on discrete games. We have collected together four excellent papers dealing with issues related to this important topic that lies at the intersection of marketing and economics. Two of the papers in the special issue deal with Bayesian estimation of discrete games, with Narayanan focusing on games of complete information and Misra focusing on games of incomplete information.

The other two papers deal with applications of interest to marketers. The paper by Orhun investigates the geographic positioning of supermarkets in the presence of both complete (perfect) and incomplete (imperfect) information, and demonstrates the importance of allowing for location-specific complete information. The paper by Data and Sudhir examines the influence of zoning restrictions on store entry, location and format choices.

Special thanks go to Sanjog Misra for his help in organizing and soliciting papers for this special issue. We hope you enjoy the papers and find this issue of QME to be a useful resource in your own research.

G. Allenby $(\bowtie)$

Ohio State University, 2100 Neil Ave., Columbus, OH 43210, USA

e-mail: allenby_1@fisher.osu.edu 